\title{
Simultaneous Extraction of Lead, Copper, and Cadmium from Aqueous Solution using Emulsion Liquid Membrane Technique
}

\author{
Hassan A. Shamkhia ${ }^{a^{*}}$, Amer D. Z. Albdiria ${ }^{a}$ \\ ${ }^{a}$ Chemical Engineering Department - college of Engineering - University of Al-Qadisiyah-Iraq
}

\section{ARTICLE INFO}

\section{Article history:}

Received 2 June 2020

Received in revised form 14 July 2020

Accepted 20 July 2020

\section{Keywords:}

Emulsion Liquid Membrane

Simultaneous extraction of heavy metals

Emulsion stability

Extraction efficiency

Emulsification

\begin{abstract}
A B S T R A C T
A simultaneous extraction study of lead, copper, and cadmium from diluted aqueous solution through Emulsion Liquid Membrane (ELM) technique was conducted and extensive investigations of the impact of the $\mathrm{pH}$ of the feed phase, homogenizer speed, surfactant (Span 80) and carrier (D2EHPA) concentrations, and ratio of external to membrane phase on the system stability (breakage) and removal efficiencies of $\mathrm{Pb}^{2+}, \mathrm{Cu}^{2+}, \mathrm{Cd}^{2+}$ ions were experimentally carried out. Kerosene was used as the membrane and stabilized by Sorbitan monooleate (Span 80 ) as the emulsifier. Bis-2-Ethylhexyl phosphoric acid (D2EHPA) as an extractant and $\mathrm{H}_{2} \mathrm{SO}_{4}$ as a reagent (internal phase) were utilized. Lead, Copper, and Cadmium extraction efficiencies of $100 \%, 100 \%$, and $98 \%$ were obtained respectively under specific operating conditions. The emulsion stability of the system was studied, and breakage of $1.8 \%$ under the best operating condition was obtained. High reagent $\left(\mathrm{H}_{2} \mathrm{SO}_{4}\right)$ concentration $(0.5 \mathrm{M})$ maintained the simultaneous extraction of the three heavy metals (lead, copper, and cadmium) and minimizes the probable interaction and competing mechanism between them in the extraction stage.
\end{abstract}

\section{Introduction}

Large quantities of wastewater containing heavy metals are annually dumped in the environment H. Ma et al. [1]. Heavy metals have dangerous effects on health and environment. If wastewater containing heavy metals is directly disposed to surface water, sea, and groundwater, it strongly affects the lives of organisms Begum et al. [2]. Heavy metals such as; lead, copper, cadmium, zinc, nickel, Mercury, silver, iron, Chromium, gold, Arsenic, cobalt, Molybdenum, aluminum and Manganese can be absorbed and cumulative inside body of human causing dangerous health problems Mahakal et al. [3] .Cancer, organ harm, and harm for the nervous system are examples of health problems caused by heavy metals.
In particular, Copper, Cadmium, and Lead are considered to be highly toxic minerals. Copper results in liver and kidneys damage S. N. H. D. et al. [4], Cadmium as carcinogen for humans, also affects kidneys [5][6]. Lead causes major damage to immune and nervous systems Salman et al. [7] . It also hinders children's growth.

Therefore, the removal of heavy metals from wastewaters becomes very important and several separation processes have been developed for this purpose, such as precipitation Swain et al. [8], adsorption [9][10], ionexchange Khanmohammadi et al. [11], reverse osmosis Li et al. [12], Electrodialysis and electrochemical [13][14].

* Corresponding author.

E-mail address: hassan299ali@gmail.com (Hassan A. Shamkhi) 
Emulsion Liquid Membrane (ELM) has emerged as an effective separation process used to remove heavy metals from wastewater Nemati et al. [13].

ELM mainly depends on concentration difference between external and internal phases through flexible membrane surrounding the internal phase. ELM is considered as an easy operation and low energy consumption separation process in comparison with other traditional processes such as reverse osmosis, ultrafiltration, and semi-permeable membrane techniques Hussein et al. [15].

The simplicity of ELM systems is reflected on its low operating and maintenance costs. Extraction and stripping of heavy metal are happened simultaneously when ELM is used for the removal of heavy metals from wastewaters resulting in high efficiency process Goyal et al. [16]. ELM processes can select a component from a solution containing a mixture of minerals [17][18], or remove more than one element at the same time Ammar et al. [19].

However, ELM's instability is considered as a major challenge of the process. Membrane breakage (leakage) is the main reason of the membrane instability and directly affects the overall ELM efficiency Mohammed et al. [20]. Breakage is defined as the process of leaking the internal phase of the globules, which reduces the stripping agent and consequently reduces the extraction and destabilizes the system Pfeiffer et al. [21].

ELM consists of two aqueous phases (external and internal) separates by a thin membrane of organic phase. ELM assumed as a "bubble within a bubble" the internal bubble represents the internal phase and external bubble represents external phase, where membrane (skin) separates the contents of the two bubbles (phases) from merging. External phase is treated as the feed phase [22][23] .

Choosing the appropriate membrane components determines the success of the ELM which includes the right selection of the organic composition, surfactant composition, carrier/extractant composition, and internal phase composition, These are the most important factors on which the success of the ELM system depends Abbassian et al. [24]

Carriers/extractants like D2EHPA Yanlin et al. [25] , TBP Mohammed et al. [26] or Aliquat336 Rosly et al. [27] must suitable to form complexes with the target pollutant and then extract it. The Internal phase like $\mathrm{H}_{2} \mathrm{SO}_{4}$ Chiha et al. [28], $\mathrm{HCl}$ Kusumastuti et al. [29] or $\mathrm{NaOH}$ Das et al. [30], and surfactants like span80 Zarandi et al. [31] or ECA 4360J Kumbasar et al. [17] should also choose carefully because it is the most important part of the system that is related to the stability of the emulsion. When properly selected, it leads to less breakage and swelling. In the ELM process, diluents are treated as one of the main components of the organic phase and have a critical function in ELM stability. Kerosene is one of the most used diluents by researchers because of its easy access to it and the appropriate viscosity, but it remains an environmentally unfriendly component Kumar et al. [22].

Using ELM for removing more than one or two metal ions is rarely found in the literature. This research focuses on extracting three toxic elements $(\mathrm{Pb}, \mathrm{Cu}$, and $\mathrm{Cd})$ from an aqueous solution, which mimics the wastewater of the Ad Diwaniyah refinery. The study was extended to investigate system stability and defining the best operating conditions for it. Literature shows that the $\mathrm{Pb}$ removal from wastewaters was studied by [31][32][7], the $\mathrm{Cu}$ removal from wastewaters was studied by [33][28][1], and the Cd removal from wastewaters was studied by [34][35][25].

\section{Chemicals and experimental methods}

\subsection{Chemicals}

Di-(2-Ethylhexyl) phosphoric acid (D2EHPA) as the extractant which was purchased from Sigma-Aldrich (Merck, Darmstadt, Germany). and Sorbitan monooleate (Span 80) was the non-ionic. surfactant and sulfuric acid $\left(\mathrm{H}_{2} \mathrm{SO}_{4}\right)$ was the stripping agent and both were obtained from Thomas beaker (Mumbai, India). The kerosene procured from Al-Wasat Refineries Company/Al-Diwaniya Refinery (Iraq, Al-Qadisiyah) behaved as a diluent.

The aqueous solutions were formed using the solid form of lead nitrate, Cadmium sulphate and Cupric sulphate were obtained also from Thomas beaker (Mumbai, India).

\subsection{Emulsion preparation}

The W/O emulsion was formed through two main steps; starting with adding certain ratios of span 80 and D2EHPA acid to kerosene oil and then mixing it for a short time on a magnetic mixer without heating to maintain the viscosity of the mixture, then transfer the mixture to a suitable glass beaker (use here a $200 \mathrm{ml}$ beaker) to mix with $\mathrm{H}_{2} \mathrm{SO}_{4}$ solution prepared according to certain molarity using a high-speed SR30 homogenizer. A cold-water bath used when speed higher than $12700 \mathrm{rpm}$, the speed and time are changed to obtain the best conditions.

\subsection{Procedure and mechanism extraction}

During the emulsion preparation process, the outer phase is prepared. In this study, concentrations of $10 \mathrm{ppm}$ of lead, copper and cadmium ions are taken with the $\mathrm{pH}$ setting. The emulsion phase is added to the aqueous phase to be mixed by digital mixer for 8 minutes at a speed of 250rpm, after which the samples are drawn and filtered using a filter syringe of $0.22 \mu \mathrm{m}$.

Adding carries Which is di-2-ethyl hexyl phosphoric acid (D2EHPA) in this study to the organic phase works to increase the effectiveness and selectivity of separating dissolved ions, as this extractant works on forming a complex with target metal ions to increase extraction. the process of forming complexes is the intermediary of transporting ions from the external phase to the internal phase passing through the organic phase as Fig. 1.

The extraction and stripping reactions for metals transfer through the oil phase by acidic carriers can be displayed as follows:

$\mathrm{M}^{+2}+2 \mathrm{HR}=>\mathrm{MR}_{2}+2 \mathrm{H}^{+}$
$\mathrm{MR}_{2}+2 \mathrm{H}^{+}=>2 \mathrm{HR}+\mathrm{M}^{+2}$

Where $\mathrm{HR}$ is the protonated form of acidic extractants, $\mathrm{M}^{2+}$ is the metal ions and $\mathrm{H}^{+}$the hydrogen ion.

Eq.(1) represents the extraction process that takes place by the interaction of the extracted carrier with metal ions to form complexes. As for Eq.(2), it refers to the abstraction process that takes place in the inner stage to separate the ion from the complex, while the carrier returns to form other complexes. 


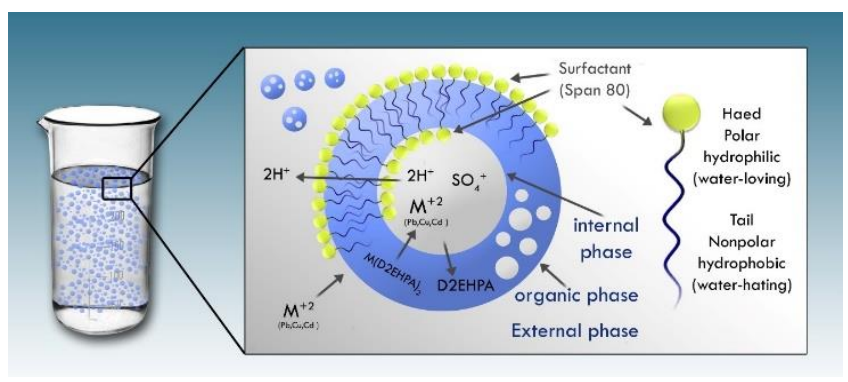

Figure 1. Extraction mechanisms of ELM system.

\subsection{Analysis and calculations}

The concentration of metal ions is measured by an atomic absorption spectrometer (Japanese 2000) where acetylene gas is used with clean and dry air. The lead element is measured with a wavelength of $(283.3 \mathrm{~nm})$ while the wavelength of copper $(324.7 \mathrm{~nm})$ and cadmium $(228.8 \mathrm{~nm})$.

The efficiency of the extraction calculated by the following equation:

$\% E=\frac{C i-C f}{C i} * 100$

Where; $\mathrm{Ci}$ : initial concentration of $\left(\mathrm{Pb}^{2+}, \mathrm{Cu}^{2+}, \mathrm{Cd}^{2+}\right)$ in aqueous external Solution, $C f$ : concentration of $\left(\mathrm{Pb}^{2+}, \mathrm{Cu}^{2+}, \mathrm{Cd}^{2+}\right)$ in aqueous external Solution after treatment.

Instability is one of the disadvantages of this technique, which reduces the extraction efficiency of the solvents. The breakage emulsion $(\% \mathrm{~B})$ indicates instability, as can be verified using the following equation [20][26][7] [36][28] :

$\% B=\frac{V I}{V I I} * 100$

where VII: initial volume of internal phase

VI: volume of internal phase leaked into the external phase and can be find from this equation:

$V I=V e x t . \frac{10^{-p H i}-10^{-p H f}}{10^{-p H f}-C_{H+}^{i n t}} * 100$

Vext : initial volume of external phase

$p H i: \mathrm{pH}$ of external phase before treated

$p H f: \mathrm{pH}$ of feed phase after a certain time of treated

$C_{H+}^{i n t}$ : the initial concentration of $\mathrm{H}^{+}$in stripping phase

The operational conditions and ranges used in this study, which affected stability and removal efficiency, are included in the Table $\mathbf{1 .}$

Table 1. Range of the variation of the operating factors during the ELM study.

\begin{tabular}{ll}
\hline Variation range & Parameter \\
$5800-24000$ & Emulsification rotating speed, rpm \\
$2-8$ & D2EHPA concentration, \% v/v \\
$0-6$ & Span 80 concentration, \% v/v \\
$2-6$ & pH of external phase \\
$100: 2-100: 15$ & external: membrane phase ratio \\
\hline
\end{tabular}

\section{Results and discussion}

\subsection{Effect of homogenizer speed on system stability and extraction efficiency of lead, copper, and cadmium}

The speed of the homogenizer has shown a considerable impact on the ELM system stability and the extraction efficiency. It was noticed that the extraction efficiency of $\mathrm{Pb}^{2+}, \mathrm{Cu}^{2+}, \mathrm{Cd}^{2+}$ increases as the speed of the homogenizer increases up to a certain limit. Beyond that limit, breakage took place and extraction efficiency declined as a function of homogenizer speed as shown in Fig. 2.

Increasing the homogenizer speed from $5800 \mathrm{rpm}$ to $16200 \mathrm{rpm}$ demonstrated a considerable decrease of the breakage from 3.8 to 1.8 , and the extraction efficiencies of $\mathrm{Pb}^{2+}, \mathrm{Cu}^{2+}, \mathrm{Cd}^{2+}$ were found to be $100 \%, 100 \%$, $98.7 \%$ respectively. Both breakage improvement and the increase of the extraction efficiencies of $\mathrm{Pb}^{2+}, \mathrm{Cu}^{2+}, \mathrm{Cd}^{2+}$ were attributed to the formation of smaller droplets size as the speed of the homogenizer increased, which resulted in an increase of the surface area available for solute transport When the speed of the homogenizer exceeded $16200 \mathrm{rpm}$, the extraction efficiency of $\mathrm{Pb}^{2+}, \mathrm{Cu}^{2+}, \mathrm{Cd}^{2+}$ started to decrease and $80 \%$ efficiency was attained at $24000 \mathrm{rpm}$. At the same time, an increase of breakage from 1.8 to 12 was demonstrated at $24000 \mathrm{rpm}$ to indicate that higher speeds of homogenizer would cause droplets collision and coalescences, through which breakage increased and system instability was evidenced.

Through a review of previous studies, it was found that the optimum speed for each research varied based on the working conditions and the extracted pollutant and its concentration, where Salman et al. [7] said that the best speed is 12,700 within $10 \mathrm{~min}$ of lead with a concentration pouring to $200 \mathrm{ppm}$, and $20000 \mathrm{rpm}$ at $4 \mathrm{~min}$ in another study Chaouchi et al. [37]

A maximum of extraction efficiency at a certain value of homogenizer speed followed by a noticeable decrease was reported in both researcher's works, and a minimum of breakage value was obtained during their course of work at the same points corresponding to the maximum extraction efficiencies

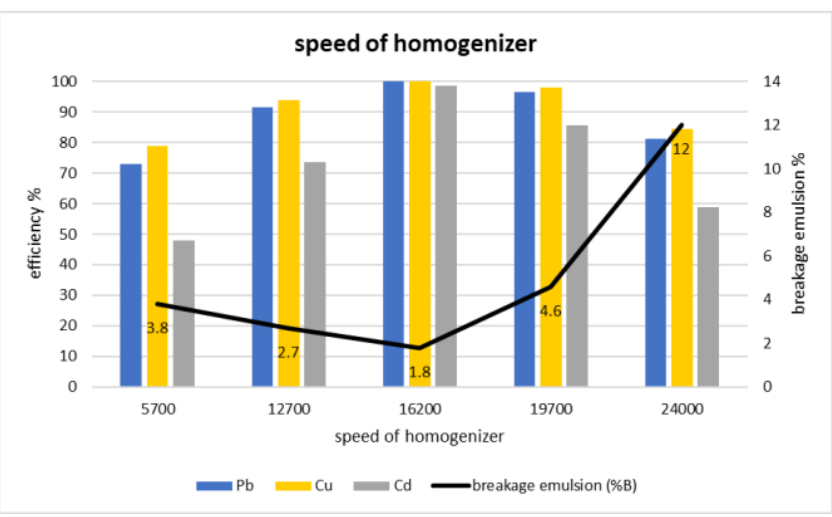

Figure 2. Effect of homogenizer speed on the extraction efficiency and membrane breakage (time of homogenizer : $10 \mathrm{~min}$, span80:4\%(v/v), 0.5 $\mathrm{M} \mathrm{H}_{2} \mathrm{SO}_{4}$, internal to organic ratio: 1, D2EHPA: $4 \%(\mathrm{v} / \mathrm{v})$, feed pH:4, $8 \mathrm{~min}$ and $250 \mathrm{rpm}$ in digital mixer, feed to emulsion ratio: 100/10). 


\subsection{Effect of extractant concentration on system stability and extraction efficiency of lead, copper, and cadmium}

Di-(2-ethylhexyl) phosphoric acid (D2EHPA) was used as a carrier to facilitate the transport of organic and inorganic pollutants. D2EHPA has high ability to form complexes with $\mathrm{Pb}^{2+}, \mathrm{Cu}^{2+}, \mathrm{Cd}^{2+}$ ions Hussein et al. [15] and consequently increases the extraction efficiency. A range of $2-8 \%$ D2EHPA to Kerosene volume ratio was investigated to determine the best value of it. As shown in Fig. 3, increasing the D2EHPA to Kerosene volume ratio from $2 \%$ to $4 \%$ resulted in a considerable increase of the extraction efficiencies of $\mathrm{Pb}^{2+}, \mathrm{Cu}^{2+}, \mathrm{Cd}^{2+}$ from $75 \%, 75 \%, 41 \%$ to $100 \%, 100 \%, 98 \%$ respectively. The breakage dropped from 3.8 to 1.8 to indicate better system stability. However, when we continued increasing the volume ratio, a decrease in extraction efficiencies was observed and an increase of breakage value was noticed to indicate system instability.

Increasing the volume ratio led to an increase of the extractant increased to contribute to membrane viscosity increase and the formation of larger globules which promote swelling phenomenon Sengupta et al. [33].

The percentage of the volume ratio of $4 \%$ was found to outperform in the extraction of $\mathrm{Pb}^{2+}, \mathrm{Cu}^{2+}, \mathrm{Cd}^{2+}$ ions from the feed phase at the same time, while different volume ratios were reported when those ions were treated

separately[7][28][25] . For $\mathrm{Pb}^{2+}$ ions, it was reported to be $4 \%$ using D2EHPA as a carrier Salman et al. [7]. For $\mathrm{Cu}^{2+}$ ions, it was reported to be $20 \%$ Chiha et al. [28], and for $\mathrm{Cd}^{2+}$ ions, the volume ratio was reported to be $4.4 \%$ Yanlin et al. [25].

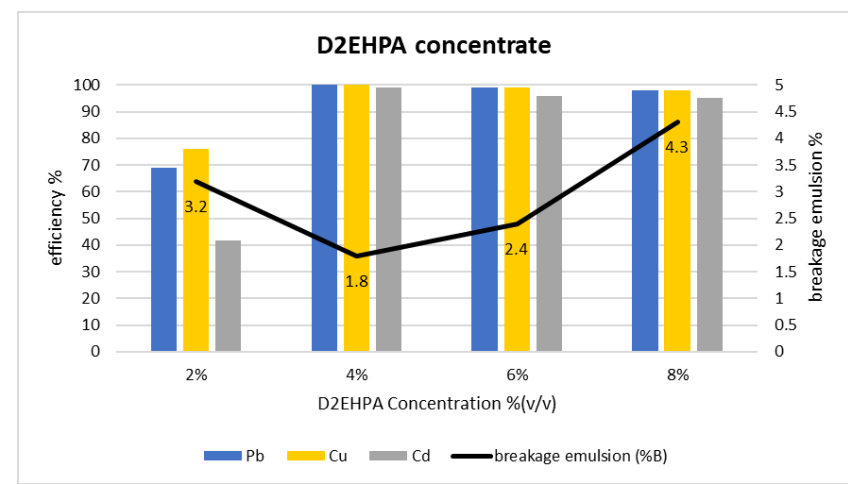

Figure 3. Effect of extractant concentration on the extraction efficiency and membrane breakage (time of homogenizer: $10 \mathrm{~min}$, span80:4\%(v/v), $0.5 \mathrm{M} \mathrm{H}_{2} \mathrm{SO}_{4}$, internal to organic ratio: 1, homogenizer speed:16200 rpm, feed pH:4, 8 min and $250 \mathrm{rpm}$ in digital mixer , feed to emulsion ratio: $100 / 10)$.

\subsection{Effect of surfactant concentration on system stability and extraction efficiency of lead, copper, and cadmium}

The effect of the surfactant (Span 80) concentration on the breakage and the extraction efficiencies of $\mathrm{Pb}^{2+}, \mathrm{Cu}^{2+}, \mathrm{Cd}^{2+}$ ions from the feed phase were examined. The surfactant concentration was varied between $0-6 \%$ (v/v \%). Fig. 4 shows that the breakage exhibited a value of $62 \%$ for $0 \%$ surfactant (Span 80) concentration to indicate high system instability. The high instability of the system was reflected in the extraction efficiencies of the $\mathrm{Pb}^{2+}, \mathrm{Cu}^{2+}, \mathrm{Cd}^{2+}$ ions to demonstrate low extraction efficiencies of $44 \%$, $55 \%$, and $13 \%$ respectively. When the surfactant (Span 80) concentration was increased to $2 \%(\mathrm{v} / \mathrm{v} \%$ ), a significant drop of the breakage value was noticed and a value of $4.9 \%$ was obtained. However, the value of the breakage of $4.9 \%$ raised the extraction efficiencies of the $\mathrm{Pb}^{2+}, \mathrm{Cu}^{2+}, \mathrm{Cd}^{2+}$ ions to $82 \%, 85 \%, 63 \%$ respectively. The maximum extraction efficiencies of the $\mathrm{Pb}^{2+}, \mathrm{Cu}^{2+}, \mathrm{Cd}^{2+}$ ions were observed at $4 \%$ Span 80 concentration. Both $\mathrm{Pb}^{2+}$ and $\mathrm{Cu}^{2+}$ ions showed $100 \%$ extraction efficiency, while $\mathrm{Cd}^{2+}$ ions showed $98 \%$ extraction efficiency, and the breakage of the system dropped to the value of 1.8 for $4 \%$ surfactant concentration. Having continued increasing the Span 80 concentration to $6 \%(\mathrm{v} / \mathrm{v} \%)$ resulted in a decline in the extraction efficiencies of the $\mathrm{Pb}^{2+}, \mathrm{Cu}^{2+}, \mathrm{Cd}^{2+}$ ions to demonstrate $76 \%, 78 \%$, and $71 \%$ extraction efficiencies respectively. The breakage also witnessed small increase to a value of 2.3 to indicate slight deterioration of system stability.

Some studies have reached the same conclusion but lead ions only that the surfactant concentration must not exceed $4 \% \mathrm{v} / \mathrm{v}$ to obtain $99 \%$ removal efficiency Sabry et al. [32] and also $4 \%$ for extraction copper ions only Chiha et al. [28].

others offered 6.6 vol\% Span 80 the optimal choice for the liquid membrane system for extraction cadmium(II) Yanlin et al. [25] .

Although the increase of the surfactant concentration enhances the system stability and hence increases the extraction efficiency, further increase of Span 80 concentration resulted in increasing the membrane phase viscosity and a difficult transport of the $\mathrm{Pb}^{2+}, \mathrm{Cu}^{2+}, \mathrm{Cd}^{2+}$ ions through the membrane would be occurred.

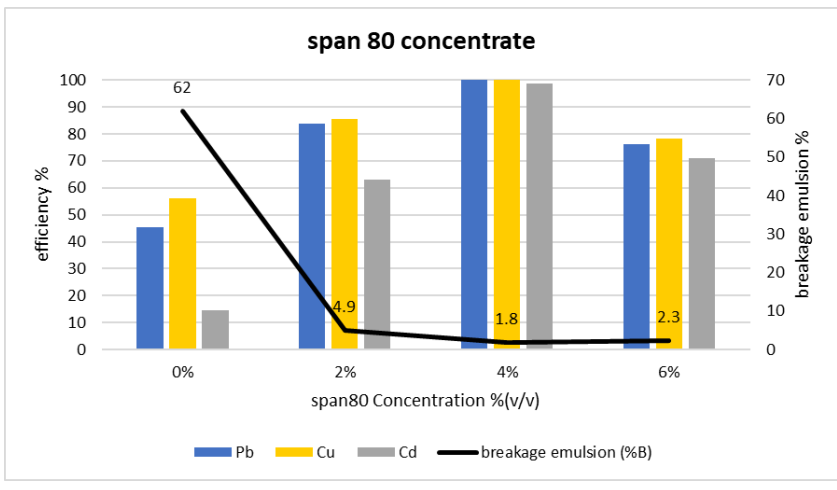

Figure 4. Effect of surfactant concentration on the extraction efficiency and membrane breakage (time of homogenizer: $10 \mathrm{~min}$, D2EHPA:4\%(v/v), $0.5 \mathrm{M} \mathrm{H}_{2} \mathrm{SO}_{4}$, internal to organic ratio: 1, homogenizer speed:16200 rpm, feed $\mathrm{pH}: 4,8 \mathrm{~min}$ and $250 \mathrm{rpm}$ in digital mixer, feed to emulsion ratio: 100/10).

\subsection{Effect of external phase pH on system stability and extraction efficiency of lead, copper, and cadmium}

Fig. 5 shows the weak dependence of the extraction efficiency of the $\mathrm{Pb}^{2+}, \mathrm{Cu}^{2+}, \mathrm{Cd}^{2+}$ ions on the $\mathrm{pH}$ change of the external phase within the range of 2-6. The low effect of the $\mathrm{pH}$ on the extraction efficiency of the $\mathrm{Pb}^{2+}$, $\mathrm{Cu}^{2+}, \mathrm{Cd}^{2+}$ ions may be due to small difference between the $\mathrm{pH}$ of the internal and external phases, and the poor performance of removal solute at low $\mathrm{pH}$ result from the contest of hydrogen ions that released from the acidic extractant in the feed phase as explained Noah et al. [38].

It is shown in Fig. 5 that the extraction efficiencies of the $\mathrm{Pb}^{2+}, \mathrm{Cu}^{2+}, \mathrm{Cd}^{2+}$ ions were $85.3 \%, 87.4 \%$, and $76.6 \%$ respectively at $\mathrm{pH} 2$, while the breakage was as high as 12.7 indicating considerable system instability. 
However, increasing $\mathrm{pH}$ value to 4 resulted in better performance of extraction and stability.

The extraction efficiencies of the $\mathrm{Pb}^{2+}, \mathrm{Cu}^{2+}, \mathrm{Cd}^{2+}$ ions were $100 \%$, $100 \%$, and $98 \%$ respectively. The breakage of 1.8 was obtained at $\mathrm{pH}$ of 4 indicating good stability of the system. When the value of $\mathrm{pH}$ exceeded 4 , the extraction efficiency decreased due to an increase of the difference of osmotic pressure which consequently stimulated the transport of water molecules to the internal phase and caused the swelling phenomenon of the membrane Laki et al. [39]. The system continued showing lesser breakage values indicating better system stability as shown in Fig. 5 .

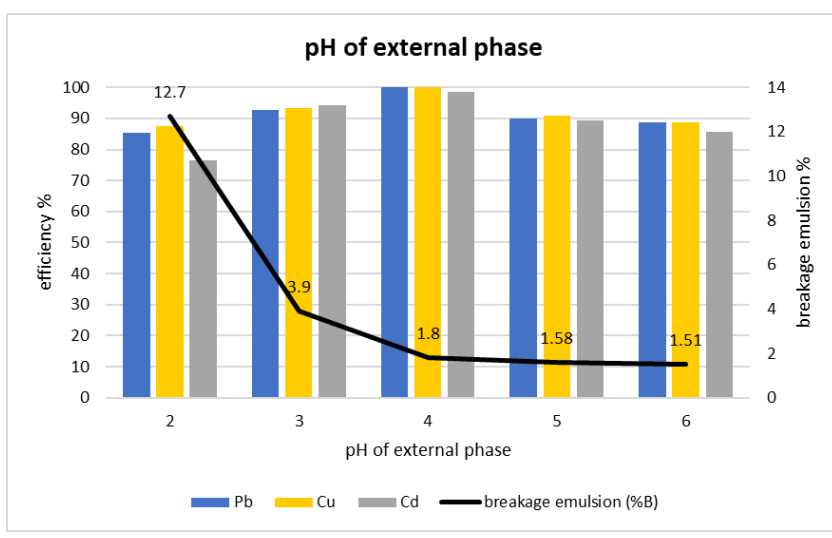

Figure 5. Effect of pH of external phase on the extraction efficiency and breakage (time of homogenizer: $10 \mathrm{~min}$, D2EHPA:4\%(v/v), 0.5M $\mathrm{H}_{2} \mathrm{SO}_{4}$, internal to organic ratio: 1, homogenizer speed:16200 rpm, span80:4\%(v/v), 8 min and $250 \mathrm{rpm}$ in digital mixer, feed to emulsion ratio: $100 / 10)$.

\subsection{Effect of external:emulsion phase ratio on system stability and extraction efficiency of lead, copper, and cadmium}

The volume ratio of the external to emulsion phases is called Treat Ratio (TR). TR was found to affect the mass transfer of the ELM system, so a range of 100:2 - 100:15 was studied to evaluate the TR effect on the system performance. As shown in Fig. 6, lower TR values gave lower extraction efficiencies of the $\mathrm{Pb}^{2+}, \mathrm{Cu}^{2+}, \mathrm{Cd}^{2+}$ ions and as TR increased to the value of 100:10, maximum extraction efficiencies for the $\mathrm{Pb}^{2+}, \mathrm{Cu}^{2+}, \mathrm{Cd}^{2+}$ ions were obtained (100\%, $100 \%$, and $98 \%$ respectively).

Beyond the value of the TR of 100:10, the efficiency decreased to lower values. System stability followed the same trend of extraction efficiency. The system stability was getting better as the TR increased from 100:2 to 100:10 to show a minimum value of 1.8 , but it slightly increased to 2.2 when the TR was increased to 100:15. The obtained results matched that reported in Salman et al. [7] .

The drop in the extraction efficiencies of the $\mathrm{Pb} 2+, \mathrm{Cu} 2+, \mathrm{Cd} 2+$ ions beyond the value of TR of 100:10 may be attributed to the swelling phenomenon of the internal globules, and consequently the decrease of the surface area available for mass transfer Mahakal et al. [3].

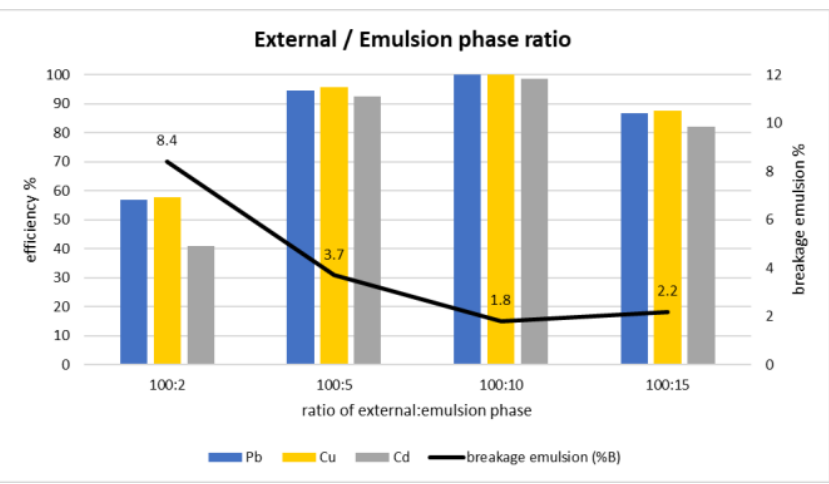

Figure 6. Effect of treat ratio on the extraction efficiency and breakage (time of homogenizer: $10 \mathrm{~min}$, D2EHPA:4\%(v/v), 0.5M $\mathrm{H}_{2} \mathrm{SO}_{4}$, internal to organic ratio: 1, homogenizer speed:16200 rpm, span80:4\%(v/v), 8 min and $250 \mathrm{rpm}$ in digital mixer, feed pH:4).

\section{Conclusions}

A successful extraction of three toxic heavy metal ions $\left(\mathrm{Pb}^{2+}, \mathrm{Cu}^{2+}, \mathrm{Cd}^{2+}\right)$ from an aqueous solution using ELM technique was carried out. The extraction efficiencies were as high as $100 \%$ for both $\mathrm{Pb}^{2+}$ and $\mathrm{Cu}^{2+}$, and $98 \%$ for $\mathrm{Cd}^{2+}$. The system had shown good stability of 1.8 values for 8 minutes period of extraction.

The system has two distinguished features other than published research; the low concentrations of the $\mathrm{Pb}^{2+}, \mathrm{Cu}^{2+}, \mathrm{Cd}^{2+}$ ions (10 ppm each) and the simultaneous extraction of the three ions. Best operating conditions for the system were found to differ from best operating conditions of each ion when extracted separately

\section{REFERENCES}

[1] H. Ma, O. Kökkılıç, and K. E. Waters, "The use of the emulsion liquid membrane technique to remove copper ions from aqueous systems using statistical experimental design," Miner. Eng., vol. 107, pp. 88-99, 2017, doi: 10.1016/j.mineng.2016.10.014.

[2] K. M. M. S. Begum, S. Venkatesan, and N. Anantharaman, "Emulsion Liquid Membrane Pertraction of Metal Ions From Aqueous Solutions and Electroplating Effluent Using Rotating Disk Contactor,' Chem. Eng. Commun., vol. 199, no. 12, pp. 1575-1595, 2012, doi: 10.1080/00986445.2012.672497.

[3] P. Mahakal and R. Deshpande, "Removal of Heavy Metal From Aqueous Wastewater By Emulsion Liquid Membrane.," Int. J. Adv. Res., vol. 6, no. 1, pp 455-463, 2018, doi: 10.21474/ijar01/6242.

[4] S. N. H. D. of Environmental, “Copper : Health Information Summary," Environ. Fact Sheet, pp. 0-2, 2013.

[5] Z. N. Abbas and A. H. Abbar, "Application of Response Surface Methodology for Optimization of Cadmium Removal from Simulated Wastewater Using a Rotating Tubular Packed Bed Electrochemical Reactor," AlQadisiyah J. Eng. Sci., vol. 13, no. 2, pp. 91-98, 2020, doi: 10.30772/qjes.v13i2.651.

[6] A. H. Sulaymon, S. A. M. Mohammed, and A. H. Abbar, "Cadmium removal from simulated chloride wastewater using a novel flow-by fixed bed electrochemical reactor: Taguchi approach," Desalin. Water Treat., vol. 74, pp. 197-206, 2017, doi: 10.5004/dwt.2017.20565.

[7] H. M. Salman and A. A. Mohammed, "Extraction of lead ions from aqueous solution by co-stabilization mechanisms of magnetic Fe $2 \mathrm{O} 3$ particles and nonionic surfactants in emulsion liquid membrane," Colloids Surfaces A Physicochem. Eng. Asp., vol. 568, no. December 2018, pp. 301-310, 2019, doi: 10.1016/j.colsurfa.2019.02.018.

[8] B. Swain, J. Jeong, S. K. Kim, and J. C. Lee, "Separation of platinum and palladium from chloride solution by solvent extraction using Alamine 300," 
Hydrometallurgy, vol. 104, no. 1, pp. 1-7, 2010, doi: 10.1016/j.hydromet.2010.03.013.

[9] M. Barsbay, P. A. Kavakl1, S. Tilki, C. Kavakl1, and O. Güven, "Porous cellulosic adsorbent for the removal of $\mathrm{Cd}$ (II), $\mathrm{Pb}$ (II) and $\mathrm{Cu}$ (II) ions from aqueous media," Radiat. Phys. Chem., vol. 142, no. October 2016, pp. 70-76, 2018, doi: 10.1016/j.radphyschem.2017.03.037.

[10] W. Kaewprachum, S. Wongsakulphasatch, W. Kiatkittipong, A. Striolo, C. K. Cheng, and S. Assabumrungrat, "SDS modified mesoporous silica MCM-41 for the adsorption of $\mathrm{Cu} 2+, \mathrm{Cd} 2+, \mathrm{Zn} 2+$ from aqueous systems," J. Environ. Chem. Eng., no. September 2018, p. 102920, 2019, doi: 10.1016/j.jece.2019.102920.

[11] H. Khanmohammadi, B. Bayati, J. R.- Shahrouzi, and A. Babaluo, "Journal of Environmental Chemical Engineering Molecular simulation of the ion exchange behavior of $\mathrm{Cu} 2+, \mathrm{Cd} 2+$ and $\mathrm{Pb} 2+$ ions on di ff erent zeolites exchanged with sodium," J. Environ. Chem. Eng., vol. 7, no. 3, p. 103040, 2019, doi: 10.1016/j.jece.2019.103040.

[12] Y. Li, Z. Xu, S. Liu, J. Zhang, and X. Yang, "Molecular simulation of reverse osmosis for heavy metal ions using functionalized nanoporous graphenes," Comput. Mater. Sci., vol. 139, pp. 65-74, 2017, doi: 10.1016/j.commatsci.2017.07.032.

[13] M. Nemati, S. M. Hosseini, and M. Shabanian, "Novel electrodialysis cation exchange membrane prepared by 2 -acrylamido-2-methylpropane sulfonic acid; heavy metal ions removal," J. Hazard. Mater., vol. 337, pp. 90-104, 2017, doi: 10.1016/j.jhazmat.2017.04.074.

[14] J. H. Hemeidan and A. H. Abbar, "Electrochemical removal of copper from a simulated wastewater using a rotating tubular packed bed of woven screens electrode," Al-Qadisiyah J. Eng. Sci., vol. 12, no. 2, pp. 127-134, 2019, doi: 10.30772/qjes.v12i2.601.

[15] M. A. Hussein, A. A. Mohammed, and M. A. Atiya, "Application of emulsion and Pickering emulsion liquid membrane technique for wastewater treatment: an overview," Environ. Sci. Pollut. Res., vol. 26, no. 36, pp. 36184 36204, 2019, doi: 10.1007/s11356-019-06652-3.

[16] R. K. Goyal, N. S. Jayakumar, and M. A. Hashim, "Chromium removal by emulsion liquid membrane using [BMIM]+[NTf2]- as stabilizer and TOMAC as extractant," Desalination, vol. 278, no. 1-3. pp. 50-56, 2011, doi: 10.1016/j.desal.2011.05.001.

[17] R. A. Kumbasar, "Selective extraction of cobalt from strong acidic solutions containing cobalt and nickel through emulsion liquid membrane using TIOA as carrier," J. Ind. Eng. Chem., vol. 18, no. 6, pp. 2076-2082, 2012, doi: 10.1016/j.jiec.2012.05.028.

[18] A. La- and R. A. Kumbasar, "Selective extraction and concentration of chromium ( VI ) from acidic solutions containing various metal ions through emulsion liquid membranes using," J. Ind. Eng. Chem., vol. 16, no. 5, pp. 829836, 2010, doi: 10.1016/j.jiec.2010.05.004.

[19] S. H. Ammar, H. G. Attia, and A. K. D. Affat, "Extraction of metal ions mixture cadmium, iron, zinc and copper from aqueous solutions using emulsion liquid membrane technique,” 2012 1st Natl. Conf. Eng. Sci. FNCES 2012, no. 1, 2012, doi: 10.1109/NCES.2012.6740483.

[20] A. A. Mohammed, H. M. Selman, and G. Abukhanafer, "Liquid surfactant membrane for lead separation from aqueous solution: Studies on emulsion stability and extraction efficiency," J. Environ. Chem. Eng., vol. 6, no. 6, pp. 6923-6930, 2018, doi: 10.1016/j.jece.2018.10.021.

[21] R. M. Pfeiffer and A. L. Bunge, "Calculating leakage in emulsion liquid membrane systems from $\mathrm{pH}$ measurements," Sep. Purif. Technol., vol. 235, no. July 2019, 2020, doi: 10.1016/j.seppur.2019.116162.

[22] A. Kumar, A. Thakur, and P. S. Panesar, "A review on emulsion liquid membrane (ELM) for the treatment of various industrial effluent streams," Rev. Environ. Sci. Biotechnol., vol. 18, no. 1, pp. 153-182, 2019, doi: 10.1007/s11157-019-09492-2.

[23] P. Kazemi, M. Peydayesh, A. Bandegi, T. Mohammadi, and O. Bakhtiari, "Pertraction of methylene blue using a mixture of D2EHPA/M2EHPA and sesame oil as a liquid membrane," Chem. Pap., vol. 67, no. 7, pp. 722-729, 2013, doi: 10.2478/s11696-013-0374-0.

[24] K. Abbassian and A. Kargari, "Effect of polymer addition to membrane phase to improve the stability of emulsion liquid membrane for phenol pertraction," Desalin. Water Treat., vol. 57, no. 7, pp. 2942-2951, 2016, doi: 10.1080/19443994.2014.983981.
[25] Z. Yanlin, L. Peihong, Z. Qiuyun, and C. Wen, "Separation of cadmium(II) from spent nickel/cadmium battery by emulsion liquid membrane," Can. J. Chem. Eng., vol. 88, no. 1, pp. 95-100, 2010, doi: 10.1002/cjce.20251.

[26] A. A. Mohammed, M. A. Atiya, and M. A. Hussein, "Studies on membrane stability and extraction of ciprofloxacin from aqueous solution using pickering emulsion liquid membrane stabilized by magnetic nano-Fe2O3," Colloids Surfaces A Physicochem. Eng. Asp., vol. 585, no. August 2019, p. 124044, 2020, doi: 10.1016/j.colsurfa.2019.124044.

[27] M. B. Rosly, N. Jusoh, N. Othman, H. A. Rahman, N. F. M. Noah, and R. N. R. Sulaiman, "Synergism of Aliquat336-D2EHPA as carrier on the selectivity of organic compound dyes extraction via emulsion liquid membrane process," Sep. Purif. Technol., vol. 239, no. June 2019, p. 116527, 2020, doi: 10.1016/j.seppur.2020.116527.

[28] M. Chiha, O. Hamdaoui, F. Ahmedchekkat, and C. Pétrier, "Study on ultrasonically assisted emulsification and recovery of copper(II) from wastewater using an emulsion liquid membrane process," Ultrason. Sonochem., vol. 17, no. 2, pp. 318-325, 2010, doi: 10.1016/j.ultsonch.2009.09.001.

[29] A. Kusumastuti, S. Anis, R. Syamwil, and A. L. Ahmad, "Emulsion liquid membrane for textile dyes removal: Extraction process,” J. Phys. Sci., vol. 29, pp. 175-184, 2018, doi: 10.21315/jps2018.29.s2.13.

[30] C. Das, M. Rungta, G. Arya, S. DasGupta, and S. De, "Removal of dyes and their mixtures from aqueous solution using liquid emulsion membrane," $\mathrm{J}$. Hazard. Mater., vol. 159, no. 2-3, pp. 365-371, 2008, doi: 10.1016/j.jhazmat.2008.02.027.

[31] M. N. Zarandi and A. Soltani, "Emulsion Liquid Membrane Design in Vitro for Removal of Lead from Aqueous Solution," Orient. J. Chem., vol. 34, no. 6, pp. 2747-2754, 2018, doi: 10.13005/ojc/340609.

[32] R. Sabry, A. Hafez, M. Khedr, and A. El-Hassanin, "Removal of lead by an emulsion liquid membrane. Part I," Desalination, vol. 212, no. 1-3, pp. 165-175, 2007, doi: 10.1016/j.desal.2006.11.006.

[33] B. Sengupta, M. S. Bhakhar, and R. Sengupta, "Extraction of copper from ammoniacal solutions into emulsion liquid membranes using LIX 84 I®," Hydrometallurgy, vol. 89, no. 3-4, pp. 311-318, 2007, doi: 10.1016/j.hydromet.2007.08.001

[34] A. L. Ahmad, M. M. H. Shah Buddin, B. S. Ooi, and A. Kusumastuti, "Utilization of environmentally benign emulsion liquid membrane (ELM) for cadmium extraction from aqueous solution," J. Water Process Eng., vol. 15, pp. 26-30, 2017, doi: 10.1016/j.jwpe.2016.05.010.

[35] A. Benderrag, B. Haddou, M. Daaou, H. Benkhedja, B. Bounaceur, and M. Kameche, "Experimental and modeling studies on Cd (II) ions extraction by emulsion liquid membrane using Triton X-100 as biodegradable surfactant," J. Environ. Chem. Eng., vol. 7, no. 3, 2019, doi: 10.1016/j.jece.2019.103166.

[36] M. Chiha, M. H. Samar, and O. Hamdaoui, "Extraction of chromium (VI) from sulphuric acid aqueous solutions by a liquid surfactant membrane (LSM)," Desalination, vol. 194, no. $1-3, \quad$ pp. 69-80, 2006, doi: 10.1016/j.desal.2005.10.025.

[37] S. Chaouchi and O. Hamdaoui, "Extraction of Priority Pollutant 4Nitrophenol from Water by Emulsion Liquid Membrane: Emulsion Stability, Effect of Operational Conditions and Membrane Reuse," J. Dispers. Sci. Technol., vol. 35, no. 9, pp. 1278-1288, 2014, doi: 10.1080/01932691.2013.844704.

[38] N. F. M. Noah, N. Othman, and N. Jusoh, "Highly selective transport of palladium from electroplating wastewater using emulsion liquid membrane process," J. Taiwan Inst. Chem. Eng., vol. 64, pp. 134-141, 2016, doi: 10.1016/j.jtice.2016.03.047.

[39] S. Laki and A. Kargari, "Extraction of silver ions from aqueous solutions by emulsion liquid membrane,” J. Membr. Sci. Res., vol. 2, no. 1, pp. 33-40, 2016, doi: 10.22079/jmsr.2016.15876. 